\title{
MATERNAL MORTALITY AT A REFERRAL CENTRE IN ANDHRA PRADESH: A FIVE YEAR STUDY
}

\author{
Prasad Usha1, Kasireddi Venkata Sita Mahalakshmi Sandhya Devi²
}

${ }^{1}$ Assistant Professor, Department of Obstetrics and Gynaecology, Andhra Medical College, Visakhapatnam, Andhra Pradesh. ${ }^{2}$ Associate Professor, Department of Obstetrics and Gynaecology, Andhra Medical College, Visakhapatnam, Andhra Pradesh.

\section{ABSTRACT}

\section{BACKGROUND}

India is among those countries, which has a very high maternal mortality ratio. Most maternal deaths are preventable. The causes vary from region to region.

\author{
AIM \\ To study factors involved in maternal deaths, especially the preventable factors so as to focus on them in reducing maternal \\ deaths.
}

\section{MATERIALS AND METHODS}

This is a cross sectional hospital based study conducted at a tertiary care centre for a period of 5 years from January 2011 to January 2015. A total of 43 maternal deaths occurred during this period. The live birth was 42,456.

\section{RESULTS}

In 2011, the MMR was 96.37 and 2015 it was 91.99. During the 5-year period, there was no change in the MMR suggesting that interventions during this period had no significant difference in MMR. Haemorrhage is the leading direct cause of death [30.23\%] followed by thromboembolism [25.58\%]. Indirect cause for maternal mortality is anaemia (67.44\%).

\section{CONCLUSION}

Most maternal deaths are preventable by proper counselling, adequate health care in the community and transport facilities. Infrastructure in a tertiary care hospital needs to be upgraded to meet the demands.

\section{KEYWORDS}

Maternal Deaths, Direct and Indirect Causes, Haemorrhage, Thromboembolism, Anaemia.

HOW TO CITE THIS ARTICLE: Usha P, Devi KVSMS. Maternal mortality at a referral centre in Andhra Pradesh: a five year study. J. Evolution Med. Dent. Sci. 2016;5(41):2491-2493, DOI: 10.14260/jemds/2016/581

\section{INTRODUCTION}

India accounts for the maximum number of maternal deaths in the world - 17 percent or nearly 50,000 of the 2.89 lakh women who died as a result of complications due to pregnancy or childbearing in 2013. Nigeria is the second with nearly 40,000 . In contrast, China with the largest population in the world reported 5,900 maternal deaths in 2013 mainly due to its "one-child policy."

Though India has seen a dramatic fall in Maternal Mortality Rate (MMR) by 59\% between 1990 and 2008, the country is still home to the highest number of women dying during childbirth across the world. India's MMR stood at 570 in 1990, which fell to 470 per 100,000 live births in 1995, 390 in 2000, 280 in 2005 and 230 in 2008. India, which has seen an annual decrease of MMR by $4.9 \%$ since 1990 , now records 63,000 maternal deaths a year. According to the latest report, "Trends in Maternal Mortality," released jointly by WHO, UNICEF, UNFPA and World Bank, just days before Who's Who of the Planet meet at New York for the all-important Millennium Development Goals (MDG) meeting, the number of women dying due to complications during pregnancy and

Financial or Other, Competing Interest: None.

Submission 04-04-2016, Peer Review 30-04-2016,

Acceptance 07-05-2016, Published 20-05-2016.

Corresponding Author:

Prasad Usha,

49-3-3, Lalithanagar,

Visakhapatnam,

Andhra Pradesh.

E-mail: ushaprasad411@gmail.com

DOI: $10.14260 /$ jemds/2016/581 childbirth has decreased by $34 \%$ from an estimated 5.46 lakhs in 1990 to 3.58 lakhs in 2008. According to most recent censes 2,87,000 women die every year. More than 800 women die per day, more than 30 die every hour. More than 85\% die in Sub-Saharan and South Asian regions.[1]

The rate of decline of maternal deaths in India is far from satisfactory. Preeclampsia, postpartum haemorrhage and sepsis are the most important direct causes of maternal death.[2,3] Anaemia is an important indirect cause. In order to encourage the international community to address this challenge, maternal mortality reduction was included as one of the Millennium Development Goals, MDG 5. The target of MDG 5 is to reduce Maternal Mortality Ratio (MMR) by 75\% from 1990 to 2015. The decline in MMR from 1990-2010 is $47 \%$ (global scenario) and $60 \%$ (Indian scenario). Going by this pace, we would achieve the MMR of 195 by the year 2012 and of 160 by 2015, far from the NRHM goal of 100 per 100,000 live births by 2012 .

\section{MATERIALS AND METHODS}

This is a cross sectional hospital based study conducted at tertiary care centre for a period of 5 years from January 2011 to January 2015. A total of 43 maternal deaths occurred during this period. The live birth was 42,456 . The direct and indirect causes for maternal death are analysed.

\section{RESULTS}

Demographic factors associated with increased maternal deaths were age between $19-24$ years [53.48\%], primigravida [79.06\%] and low socioeconomic status [83.72\%] [Table 1].

In 2011, the MMR was 96.37 and 2015 it was 91.99. During the 5-year period, there was no change in the MMR 
suggesting that interventions during this period had no significant difference in MMR [Table 2]. Regarding the period of pregnancy at the time of death, $60.46 \%$ occurred during intrapartum or less than 24 hours following delivery showing that this is the most critical period followed by postpartum period 25.58\% [Table 3].

Haemorrhage is the leading direct cause of death [30.23\%] followed by thromboembolism [25.58\%]. Sepsis incidence was low as the deliveries were conducted at a tertiary care centre [4.6\%]. Indirect cause for maternal mortality is anaemia $(67.44 \%)$ [Table 4$]$.

\begin{tabular}{|c|c|c|}
\hline $\begin{array}{c}\text { Demographic } \\
\text { Factor }\end{array}$ & $\begin{array}{c}\text { No. of Maternal } \\
\text { Deaths }\end{array}$ & Percentage \\
\hline Age & & \\
$<19$ yrs & 12 & {$[27.9 \%]$} \\
$19-24$ yrs & 23 & {$[53.48 \%]$} \\
$25-29$ yrs & 5 & {$[11.62 \%]$} \\
$>30$ yrs & 3 & {$[6.9 \%]$} \\
\hline Parity & 34 & {$[79.06 \%]$} \\
Primi & 9 & {$[20.93 \%]$} \\
Multi $[2-4]$ & 0 & {$[0 \%]$} \\
Grand multi & 2 & {$[4.6 \%]$} \\
\hline SE Status & 5 & {$[11.62 \%]$} \\
Upper & 36 & {$[83.72 \%]$} \\
Middle & & \\
Lower & \multicolumn{2}{|c|}{ Table 1: Demographic Factors } \\
\hline \multicolumn{2}{|c}{}
\end{tabular}

\begin{tabular}{|c|c|c|c|c|}
\hline Year & $\begin{array}{c}\text { Live } \\
\text { Births }\end{array}$ & $\begin{array}{c}\text { Maternal } \\
\text { Deaths }\end{array}$ & $\begin{array}{c}\text { MMR } \\
\text { (Hospital) }\end{array}$ & $\begin{array}{c}\text { National } \\
\text { MMR }\end{array}$ \\
\hline 2011 & 8,301 & 8 & 96.37 & 206 \\
\hline 2012 & 8,619 & 9 & 104.42 & 197 \\
\hline 2013 & 8,431 & 11 & 130.47 & 189 \\
\hline 2014 & 8,409 & 7 & 83.244 & 181 \\
\hline 2015 & 8,696 & 8 & 91.99 & 174 \\
\hline \multicolumn{5}{|c|}{ Table 2: Year Wise MMR } \\
\hline & $\mathbf{4 2 , 4 5 6}$ & $\mathbf{4 3}$ & \\
\hline
\end{tabular}

\begin{tabular}{|c|c|c|}
\hline Period & $\begin{array}{c}\text { No. of } \\
\text { Deaths }\end{array}$ & Percentage \\
\hline Antenatal $<20$ weeks & 2 & $4.65 \%$ \\
\hline Antenatal $>20$ weeks & 4 & $9.3 \%$ \\
\hline $\begin{array}{c}\text { Intrapartum } /<24 \text { hrs } \\
\text { postpartum }\end{array}$ & 26 & $60.46 \%$ \\
\hline Postpartum $>24$ hrs & 11 & $25.58 \%$ \\
\hline Table 3: Period of Pregnancy at the Time of Death \\
\hline
\end{tabular}

\begin{tabular}{|c|c|c|}
\hline Cause of Death & No. of Maternal Deaths & Percentage \\
\hline Direct & 13 & \\
Haemorrhage & 3 & {$[30.23 \%]$} \\
Eclampsia & 11 & {$[6.97 \%]$} \\
Thromboembolism & 9 & {$[25.58 \%]$} \\
CVA & 2 & {$[20.93 \%]$} \\
Sepsis & 3 & {$[4.6 \%]$} \\
AF embolism & 2 & {$[6.9 \%]$} \\
Heart disease & 29 & {$[4.6 \%]$} \\
\hline Indirect & Table 4: Cause of Death \\
Anaemia (<9 gms) & {$[67.44 \%]$} \\
\hline \multicolumn{2}{|c|}{} \\
\hline
\end{tabular}

\section{DISCUSSION}

Maternal death is the death of a woman while pregnant or within 42 days of termination of pregnancy, irrespective of the duration and site of the pregnancy, from any cause related to or aggravated by the pregnancy or its management but not from accidental or incidental causes. Improving maternal health was 1 of the 8 Millennium Development Goals (MDGs) adopted by the international community in 2000 under MDG 5, countries committed to reducing maternal mortality by 3 quarters between 1990 and 2015 . Since 1990, the number of maternal deaths worldwide has dropped by 43\%. Between 2016 and 2030, as part of the Sustainable Development Agenda, the target is to reduce the global maternal mortality ratio to less than 70 per 100,000 live births.

Almost all maternal deaths (99\%) occur in developing countries.[4,5] India is among those countries, which has a very high maternal mortality ratio. Developed countries in contrast have a maternal mortality ratio of around 20 per 100,000 live births.[6]

In the present study, haemorrhage and hypertensive disorders of pregnancy are the major direct causes, similar to studies by Nikhil Purandare et al[7] Surendranath Panda et al. ${ }^{[8]}$ Most deaths in our study occurred in spite of availability of blood bank facility and availability of anaesthetist round the clock. The major factor in these cases was pre-existing anaemia, which was not corrected even at term reflecting poor antenatal attendance and refusal to seek treatment. In our study, anaemia is the leading indirect cause of maternal mortality which correlates with the results from Surendranath Panda et al (2000).[8] and Verma Ashok et al (2008).[9]

Ratan Das et al[10] in their study, eclampsia accounted for $43.35 \%$ of total maternal deaths with case fatality of $4.960 \%$. The commonest mode of death in eclampsia was pulmonary oedema in the age group of 19-24 years and in primigravid. Eclampsia related deaths were mostly seen in illiterate, unbooked cases and in lower socioeconomic status.

Chakraborty $\mathrm{S}$ et al[11] recorded maternal deaths from 1989-1991; and from 2006-2008. The MMR rate came down from 1051 to 494.33 (change of $47 \%$ ) over a span of seventeen years, while the causative factors did not change their rank orders. The commonest cause being haemorrhage and eclampsia with a mean being $26.6 \%$ for haemorrhage and $27.63 \%$ for preeclampsia/eclampsia. The next important cause was jaundice $(15.78 \%)$, unsafe abortion $(6.49 \%)$ and anaemia accounted for $6.46 \%$ of maternal deaths. Credit for declining trend of MMR may be attributed to improving skills of health workers, adopting improved standards for the management of pregnancy and childbirth at different levels of health care system.

Bhaskar K Murthy et al[12] did a retrospective study of maternal mortality for 10 years period and analysed 120 maternal deaths. Most maternal deaths occurred in the age group of 20-24 years, multiparous women (56.66\%), women from rural areas (69.16\%), illiterate women (65\%), unbooked patients (83.33\%), and patients of low socioeconomic status (83.33\%). Direct causes accounted for $72.5 \%$ of maternal deaths, whereas $27.5 \%$ of maternal deaths were due to indirect causes. Madhuri Badrinath et al[13] did a retrospective study of 45 deaths from Jan 2009 to March 2014. Maternal mortality ratio and causes were analysed and compared. Over the study period, MMR was $277 / 1,00,000$ live births. The leading direct cause was sepsis (51.11\%) and indirect cause was anaemia (62.2\%). Maternal mortality can 
be prevented with proper identification and strengthening of the first referral units with equipment, adequately competent staff and blood bank can decrease maternal mortality and morbidity.

Pal Amitava et al[14] analysed causes of maternal death for 6 years from 1999 to 2004 . The maternal mortality rate was 623.46 per 100,000 live births. The major causes of maternal deaths were toxaemia (50.56\%), sepsis (18.17\%), and haemorrhage (9.72\%). Anaemia (4.18\%) and jaundice (1.84\%) were two important indirect causes of maternal deaths. More than $60 \%$ of maternal deaths were from rural areas. Emergency obstetric care, early risk screening and efficient obstetric services would decrease maternal mortality.

During the United Nations General Assembly 2015, in New York, UN Secretary-General Ban Ki-moon launched the Global Strategy for Women's, Children's and Adolescents' Health, 2016-2030.[15] The strategy is a road map for the post-2015 agenda as described by the Sustainable Development Goals and seeks to end all preventable deaths of women, children and adolescents and create an environment in which these groups not only survive, but thrive and see their environments, health and wellbeing transformed.

WHO, 2015.[15] has laid strategies to prevent maternal mortality: The strategies are to empower women, protect and support the mother-baby dyad by ensuring country ownership, universal health coverage and human rights framework to ensure high-quality reproductive, maternal and new-born services.

Death reviews, attended by all personnel (Health and administrative, public and private) involved in the care of pregnant women should be held periodically. Early intensive efforts to improve family planning, to control fertility choices, to provide safe abortion and integrated maternal health services are the most important interventions to reduce pregnancy related mortality. Unfortunately, Janani Suraksha Yojna Scheme and other schemes have put an undue stress on institutional deliveries without making an effort to promote the importance of good antenatal care and reducing maternal mortality and morbidity by early detection and treatment of preventive causes.

The Maternal Mortality Ratio - the number of maternal deaths per 100,000 live births - reduced from 212 in 2007 to 178 in 2012. UNICEF and its partners contributed to this reduction through schemes such as JSSK. UNICEF India in 2014 also supported modelling and scale up of a unique software for Maternal Death Review (MDR) in five states. The software provides timely data on the causes and location of maternal deaths. It is planned to scale up the software in 10 more states in 2015 and eventually nationwide by 2016 .

\section{CONCLUSION}

Most maternal deaths are preventable by proper counselling, adequate health care in the community and transport facilities. Infrastructure in tertiary care hospital needs to be upgraded to meet the demands. Most often blood is not available in blood banks causing delay in blood transfusion and haemorrhage related deaths. Anaemia is a major indirect factor, which unfortunately continues to be high in spite of aggressive measures by the government to reduce it.

\section{REFERENCES}

1. World health organization. Trends in maternal mortality: 1990 - 2010: WHO, UNICEF, WNFPA, and the world estimates. Geneva: WHO 2012;pgs.59.

2. Costello A, Ostin D, Manandhar D. Reducing maternal and neonatal mortality in the poorest communities. BMJ 2004;329:1166-8.

3. Registrar General of India. Maternal mortality in India: 1997-2003: trends, causes and risk factors; summary. New Delhi: Office of the Registrar General of India 2006.

4. Countdown to 2015 for maternal, newborn and child survival: accountability for maternal, newborn and child survival. Geneva: Who Health Organisation 2013;pgs 105.

5. Trends in maternal mortality: 1990-2015- Estimates developed by WHO, UNICEF, UNFPA, World Bank group and the United Nations Population Division.

6. WHO, UNICEF, UNFPA. Maternal mortality in 2000: Estimates developed by WHO, UNICEF, UNFPA. Geneva: WHO, 2003.

7. Purandare N, Chandock AS, Upadhya S, et al. Maternal mortality at a referral centre: a five year study. J Obstet Gynaecol India 2007;57(3):248-50.

8. Panda S, Das BB, Patnaik A. An investigation into maternal mortality. Paper presented at the $44^{\text {th }}$ all India congress of obstetricians and gynaecologists, Ahmedabad 28-31 December 2000.

9. Verma A, Minhas S, Sood A. A study on maternal mortality. J Obstet Gynaecol India 2008;58:226-9.

10. Das R, Biswas S. Eclampsia, the major cause of maternal mortality in eastern India. Ethiop $\mathrm{J}$ Health Sci 2015;25(2):111-6.

11. Chakraborty S, Sebanti G. Maternal mortality rate and its causes-changing trends in Kolkata, India. IJRRMS 2012;2(1):16-8.

12. Murthy BK, Murthy MB, Prabhu PM. Maternal mortality in a tertiary care hospital, a 10-year review. Int J Prev Med 2013;4(1):105-9.

13. Madhuri B, Saraswathi AK. Maternal mortality: a retrospective study. Journal of Nursing and Health Science 2015;4(2):10-3.

14. Pal A, Ray P, Hazra $S$, et al. Review of changing trends in maternal mortality in a rural medical college in west Bengal. J Obstet Gynaecol India 2005;55(6):521-4.

15. Human Reproduction Programme. Strategies toward ending preventable maternal mortality. Geneva: WHO 2015. 